\title{
əTracing the Origin of the South Asian Summer Monsoon Precipitation and Its Variability Using a Novel Lagrangian Framework $\mathscr{A}$
}

\author{
DiPANJAN DEY AND KRISTOFER DÖÖs ${ }^{\mathrm{a}}$

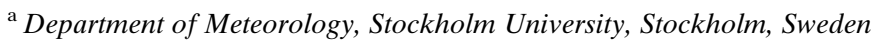

(Manuscript received 15 December 2020, in final form 2 August 2021)

\begin{abstract}
The water sources and their variability responsible for the South Asian summer monsoon precipitation were analyzed using Lagrangian atmospheric water-mass trajectories. The results indicated that evaporated waters from the central and south Indian Ocean are the major contributors to the South Asian summer monsoon rainfall, followed by the contribution from the local recycling (precipitated water that evapotranspirated from the South Asian landmass), the Arabian Sea, remote sources, and the Bay of Bengal. It was also found that although the direct contribution originating from the Bay of Bengal is small, it still provides a pathway for the atmospheric water that comes from other regions. This pathway is hence only crossing over the Bay of Bengal. The outcomes further revealed that the evaporated waters originating from the central and south Indian Ocean are responsible for the net precipitation over the coastal regions of the Ganges-Brahmaputra-Meghna Delta, northeast India, Myanmar, the foothills of the Himalayas, and central-east India. Evaporated waters from the Arabian Sea are mainly contributing to the rainfall over the western coast and west-central India. Summer monsoon precipitation due to the local recycling is primarily restricted to the Indo-Gangetic plain. No recycled precipitation was observed over the mountain chain along the west coast of India (Western Ghats). The month-to-month precipitation variation over South Asia was analyzed to be linked with the Somali low-level jet variability. The interannual variability of the South Asian summer monsoon precipitation was found to be mainly controlled by the atmospheric waters that were sourced and traveled from the central and south Indian Ocean.
\end{abstract}

KEYWORDS: Conservation equations; Hydrologic cycle; Lagrangian circulation/transport; Mass fluxes/transport; Meridional overturning circulation; Monsoons; Interannual variability

\section{Introduction}

The South Asian summer monsoon, which takes place during the months from June to September (JJAS), is a major component of the global monsoon system and associated with the seasonal movement of the tropical convergence zone over land (Sikka and Gadgil 1980). This migration of the convergence zone initiates a moisture supply chain from the ocean toward land and provides the summer monsoonal precipitation. There is an ongoing debate about how this moisture supply chain will change due to anthropogenic forcing. Most of the climate models, investigated in phase 5 of the Coupled Model Intercomparison Project (CMIP5), predict an overall increase of the South Asian summer monsoon precipitation by the end of the twenty-first century due to increased water vapor in the atmosphere from the greenhouse gas warming despite a weak/unaltered monsoonal circulation (Christensen et al. 2013; Mei et al. 2015). The observational datasets do not, however, seem to be in agreement with this increase precipitation statement (Roxy et al. 2015). The South Asian summer monsoon

๑ Denotes content that is immediately available upon publication as open access.

Supplemental information related to this paper is available at the Journals Online website: https://doi.org/10.1175/JCLI-D-200967.s1.

Corresponding author: Dipanjan Dey, dipanjan.dey@misu.su.se affects agriculture, ecosystems, hydroelectricity production, and water availability through spatial and temporal variability of precipitation (Gadgil and Kumar 2006). Thus identification of the sources and pathways of water responsible for precipitation and how it varies across spatial and temporal scales will be a key factor for understanding the uncertainties involved in model predictions. These results could also be beneficial for policy makers and billions of people through improved quality of weather forecasting.

The origin of water available for precipitation over South Asia is a challenging issue to address. Pisharoty (1965) was among the first who investigated the origin of moisture that is reaching India by analyzing a water vapor budget over the Arabian Sea. His results indicated that the evaporation from the Arabian Sea was a major source of moisture for India because water vapor flux from the eastern wall of his Arabian Sea box was much higher than that through the southern boundary. Later, Saha and Bavadekar (1973) used an improved dataset and included the effects of the precipitation, which led to the conclusion that the water vapor fluxes from the southern boundary of the Arabian Sea are instead mainly responsible for the moisture supply to the west coast of India. The divergent component of the water vapor flux fields and subjective analysis of the wind patterns could give an overall idea of the moisture source regions and pathways. This would, however, not provide any information about how much of the evaporated moisture actually precipitates, how much each ocean basin contributes to the South Asian summer precipitation,

Publisher's Note: This article was revised on 19 November 2021 to designate it as open access. 
exact quantification of the atmospheric water transport values and pathways, atmospheric water-residence times, and other details. All of these issues, nevertheless, can be achieved with a Lagrangian tracking approach.

Bosilovich and Schubert (2002) used water vapor tracers in a $3 \mathrm{D}$ atmospheric model and found that the west oceanic region (equivalent to the Arabian Sea) was the primary contributor to the South Asian monsoon precipitation followed by contribution from the south oceanic region (equivalent to the south Indian Ocean), local recycling, and the east oceanic sector (equivalent to the Bay of Bengal). Gimeno et al. (2010) identified six moisture source regions responsible for the Indian subcontinent precipitation during the June to August months using a 3D Lagrangian particle dispersion model, FLEXPART (Stohl and James 2004), in which the particles were advected by the operational European Centre for Medium-Range Weather Forecasts (ECMWF) wind fields over a 5-yr time period (2000-04). These locations were the Indian Ocean, the Arabian Sea, the oceanic areas over the Zanzibar and Agulhas Currents, tropical southern Africa, and the Red Sea. Ordóñez et al. (2012), using FLEXPART and the ERA-40 reanalysis dataset during 2000-04, revealed that the western and southern Indian summer precipitation is mainly sourced from the Arabian Sea and the Indian Ocean, which is then advected with the Somali low-level jet. This low-level jet is a southwesterly flow off the coast of Somalia during the summer monsoon months and is also the northern branch of the cross-equatorial flow. Mei et al. (2015), using a 2D modified Lagrangian Dynamic Recycling Model (Martinez and Dominguez 2014) that was forced with both NCEP-NCAR Reanalysis I outputs over the period 1965-2005 and CMIP5 climate model datasets (1965-2005 for the historical simulation and 2010-99 for the representative concentration pathway 8.5 scenario), reported that remote sources (including the south Indian Ocean) of moisture are the largest contributor to the South Asian summer monsoon (46\%), followed by the evapotranspirated moisture from the South Asian landmass (30.4\%), the Arabian Sea (19.6\%), and the Bay of Bengal (4\%), respectively. Pathak et al. (2017b), using the same Lagrangian model and ERA-Interim dataset during 1979-2013, found that the western Indian Ocean, the central Indian Ocean, the upper Indian Ocean, the Ganges basin, and the Red Sea are the five major moisture sources responsible for the Indian summer monsoon rainfall. The difference in results, despite using the same model, between the two studies is probably due to their nonidentical ocean and land region definitions, datasets, and time period investigated. The majority of the Lagrangian studies regarding the South Asian summer monsoon rainfall has been achieved by tracing humid air and using 2D Lagrangian models. The specific humidity change along an air-mass trajectory is then translated as evaporation/precipitation. The advantage of a 2D Lagrangian model is that it requires fewer computing resources and could run for a longer period of time. However, it neglects the vertical distribution of moisture and assumes a well-mixed atmosphere. The directional wind shear could lead to a weak or incomplete mixing of the moisture and in that case the well-mixed assumption will fail (Van der Ent et al. 2013). A study by Goessling and Reick (2012) found that the directional wind shear is maximum over the tropical regions and thus the 2D moisture tracking models are less accurate there. A major limitation in the 3D Lagrangian FLEXPART model is that it traces air with a more/less moisture in it rather than directly tracing the atmospheric mass of water itself. The interpolation of the specific humidity along the air trajectories could lead to nonphysical fluctuations in the specific humidity field due to the interpolation error and thus consequently will affect the evaporation minus precipitation $(E-P)$ values. Furthermore, it neglects the time rate of change of water mass inside the grid box (Stohl and James 2004), which is not true for synoptic (and smaller) time scales where the addition and removal of water plays an important role to determine the evaporation minus precipitation.

A new method to trace atmospheric water with Lagrangian trajectories was recently introduced (Dey and Döös 2020), where the water-mass parcels are passively advected by the 3D atmospheric water transports instead of humid air. These transports were computed with a water-mass conservation method (Dey and Döös 2019), where the vertical component includes not only the advection of moisture but also the evaporation and precipitation. This made it possible to trace the movement of the atmospheric water from the evaporating to the precipitating surfaces, or vice versa, independent of in which phase the water is in. This has previously not been achieved as most of the moist atmospheric Lagrangian models are based on moisture tracking algorithms in contrast to the present approach, where the mass of water is traced regardless of its phase. The objectives of the present study, using this new methodology, are to identify the water source regions responsible for the South Asian summer monsoon rainfall and how they vary interannually. A detailed analysis of the contribution from different ocean and land regions (Fig. 1a) to the total precipitation over the South Asian landmass was also performed.

\section{Data and methods}

\section{a. Data used}

The atmospheric water transports were calculated using the surface pressure, specific humidity, and horizontal wind velocities from the ERA-Interim reanalysis (Dee et al. 2011). However, this water transport computation omits diffusive moisture transports, specific cloud liquid water, specific cloud ice water, specific rain, and snow water content. The datasets were obtained for the years $2009-18$ with $0.75^{\circ}$ spatial resolution, 6-hourly temporal resolution $\left(\Delta t_{G}\right)$, and 60 hybrid vertical model levels. The present study uses Lagrangian trajectory model TRACMASS (Döös 1995), which requires data on model levels and not on interpolated pressure levels in order to conserve mass. The recently released atmospheric reanalysis product ERA5 (Hersbach et al. 2020) could therefore not be used in the present study, since the ERA5 data on model levels are vast in volume and slow to access due to higher spatial and temporal resolution than its precursor ERA-Interim. However, we acknowledge that using a finer-resolution (horizontal, vertical, and temporal) reanalysis product is likely to modify the quantitative results presented here. This is since the atmospheric water needs to travel at least $79 \mathrm{~km}$ in the ERA-Interim dataset to be counted as the horizontal transport, while it is 

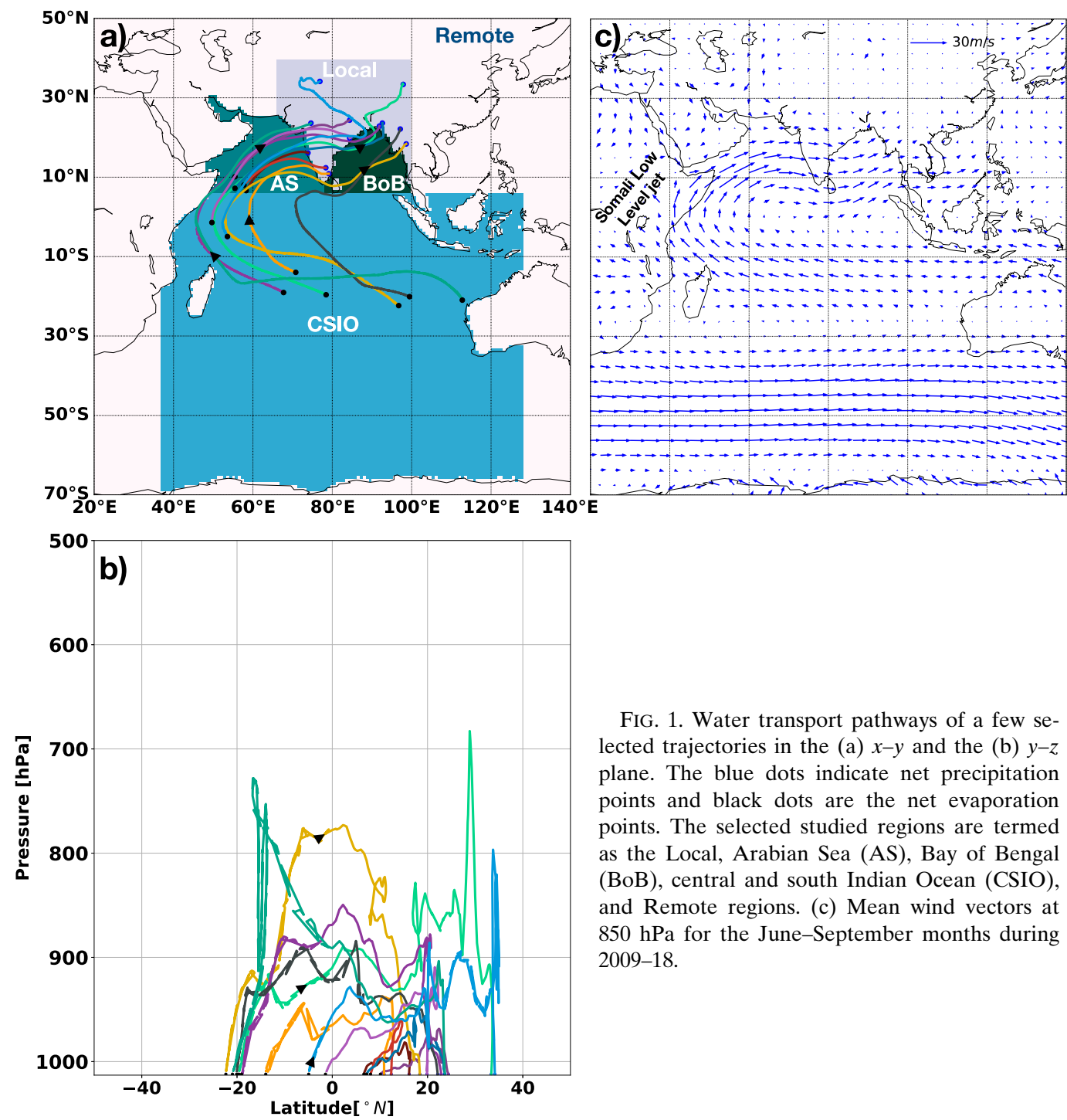

FIG. 1. Water transport pathways of a few selected trajectories in the (a) $x-y$ and the (b) $y-z$ plane. The blue dots indicate net precipitation points and black dots are the net evaporation points. The selected studied regions are termed as the Local, Arabian Sea (AS), Bay of Bengal (BoB), central and south Indian Ocean (CSIO), and Remote regions. (c) Mean wind vectors at $850 \mathrm{hPa}$ for the June-September months during 2009-18.

$31 \mathrm{~km}$ for the ERA5. As the large-scale circulation and $E-P$ patterns will not change drastically across the reanalysis datasets, we believe the main conclusions reported in the present study should not be sensitive to the product used.

\section{b. Lagrangian trajectory model TRACMASS}

The Lagrangian trajectory model TRACMASS (Döös et al. 2017) was employed in this study to investigate the sources of atmospheric water and its variability responsible for the South Asian summer monsoon precipitation. TRACMASS uses mass transports rather than velocities (Vries and Döös 2001), which makes it possible to track water-transport routes in the ocean (Döös et al. 2008) and atmospheric air-mass pathways (Kjellsson and Döös 2012). In addition, an extended version of TRACMASS was recently introduced, where atmospheric water-mass trajectories (expressed in $\mathrm{kg} \mathrm{s}^{-1}$ of water) were computed based on a water-mass conservation method (Dey and Döös 2020). It is important to note here that we are not tracing moisture in the air but the actual atmospheric mass of water itself. A detailed validation of the atmospheric water-mass version of TRACMASS was undertaken by Dey and Döös (2020). The unique characteristic of TRACMASS is that it calculates the trajectory path through each model grid box by solving the analytical solution of a differential equation both in space and time. The differential equation depends on the mass transport through the faces of a grid box and not on the velocities. The solution to a differential equation is unique and thus the trajectory calculation can be integrated forward in time and then backward in time in order to arrive exactly at the starting position as long as the stochastic parameterizations are switched off. The TRACMASS trajectory scheme is mass conserving within a grid box in the same way as the general circulation model itself. A detailed description of the Lagrangian trajectory model TRACMASS in general can be found in Döös et al. (2017).

In the present study the Lagrangian trajectories are calculated from the atmospheric water transports rather than just 
velocities through the faces of each model grid box. The advective water transports through the eastern $(U)$ and northern $(V)$ faces of a grid box, which are bounded by the zonal $(i)$, meridional $(j)$, and vertical $(k)$ faces at time step $n$,

$$
\begin{aligned}
U_{i, j, k}^{n} & =q_{i, j, k}^{n} u_{i, j, k}^{n} \Delta y_{i, j} \Delta p_{i, j, k}^{n} / g, \\
V_{i, j, k}^{n} & =q_{i, j, k}^{n} v_{i, j, k}^{n} \Delta x_{i, j} \Delta p_{i, j, k}^{n} / g,
\end{aligned}
$$

where $q$ is the specific humidity $\left(\mathrm{kg} \mathrm{kg}^{-1}\right)$ and $u$ and $v$ are the zonal and meridional wind velocities $\left(\mathrm{m} \mathrm{s}^{-1}\right)$, respectively. The longitudinal and latitudinal grid lengths are given by $\Delta x$ and $\Delta y(\mathrm{~m})$, the gravitational acceleration is denoted $g\left(\mathrm{~m} \mathrm{~s}^{-2}\right)$, and $\Delta p$ is the pressure level thickness $(\mathrm{Pa})$. Thus the horizontal water transports through the lateral faces of a model grid box have the unit of kilograms per second $\left(\mathrm{kg} \mathrm{s}^{-1}\right)$ of water. The hydrostatic equation

$$
\Delta p_{i, j, k}^{n}=\rho_{i, j, k}^{n} g \Delta z_{i, j, k}^{n}
$$

has been used in Eqs. (1) and (2). Note that the diffusive moisture transports and time correlations (due to the fluctuations shorter than the model stored time interval) are omitted in this computation. This is since the ERA-Interim product does not provide publicly the diffusive moisture transport along model levels and the output frequency for the analyses is restricted to $6 \mathrm{~h}$. Conservation of water mass yields that the rate of change of the water-mass content of a box is equal to the water transports though its faces:

$$
\frac{\partial Q_{i, j, k}}{\partial t}=U_{i-1, j, k}-U_{i, j, k}+V_{i, j-1, k}-V_{i, j, k}+W_{i, j, k-1}-W_{i, j, k},
$$

where $Q$ is the water-mass content $(\mathrm{kg})$ of a model grid box and $W$ is the vertical water transport through its uppermost face. It is important to emphasize here that the usage of the atmospheric water-mass conservation and omission of the horizontal advection of the cloud liquid and ice water will result in an immediate transport of the condensed cloud waters at the bottom of each grid box. Thus the calculated vertical water transport at each level will consist of not only vertical advection of moisture but also the vertical water transport of cloud liquid water and ice.

The quantity $Q$ was calculated by multiplying the specific humidity with the air mass which yields

$$
Q_{i, j, k}^{n}=q_{i, j, k}^{n} \Delta x_{i, j} \Delta y_{i, j} \Delta p_{i, j, k}^{n} / g .
$$

Rearranging Eq. (4) and using the expression from Eq. (5) results in

$$
\begin{aligned}
W_{i, j, k-1}^{n}= & W_{i, j, k}^{n}+\left[U_{i, j, k}^{n}-U_{i-1, j, k}^{n}+V_{i, j, k}^{n}-V_{i, j-1, k}^{n}\right. \\
& \left.+\frac{\left(\Delta p_{i, j, k}^{n} q_{i, j, k}^{n}-\Delta p_{i, j, k}^{n-1} q_{i, j, k}^{n-1}\right)}{g \Delta t_{G}} \Delta x_{i, j} \Delta y_{i, j}\right]
\end{aligned}
$$

where $\Delta t_{G}$ is the time interval between model stored fields. Equation (6) indicates that the values of $W$ at all vertical levels can be computed by integrating the equation downward from the top of the atmosphere, where the vertical water transport is assumed to be zero. At the surface $W_{i, j, 0}^{n}$ should thus be equal to the evaporation minus precipitation $(E-P)$, which was shown to be the case by Dey and Döös (2020). This matching at the sea surface validated the present method and the associated approximations.

The zonal, meridional, and vertical water transport fields, computed from Eqs. (1), (2), and (6) respectively, are used by the TRACMASS model in order to calculate the atmospheric water trajectories. A TRACMASS trajectory conserves its mass transport throughout its entire journey, which makes it possible to compute overturning streamfunctions between source and sink regions. A Lagrangian overturning water-mass streamfunction (Blanke et al. 1999) was calculated from the trajectories (Fig. 2) to evaluate the water transport in the meridional-vertical coordinates during the summer monsoon months. This can be expressed as

$$
\psi_{j, k}=\sum_{k^{\prime}=k}^{k z} \sum_{i} \sum_{m} T_{i, j, k^{\prime}, m}^{y},
$$

where $T_{i, j, k^{\prime}, m}^{y}$ is the Lagrangian water transport by the trajectory index $m$ through the zonal-vertical grid box face. The Lagrangian water transport integration both zonally and vertically down from top of the atmosphere $(k=k z$ is the highest vertical model level at $0.1 \mathrm{hPa}$ ) results in open streamlines at the surface due to atmospheric water source (evaporation) and sink (precipitation) regions. A transport weighted average atmospheric water residence time $(\tau)$ was also calculated and mapped from the atmospheric water-mass trajectories according to

$$
\tau_{i, j}=\frac{\sum_{m=1}^{M}\left[\left(t_{m}^{P}-t_{m}^{E}\right) T_{i, j, m}^{z}\right]}{\sum_{m=1}^{M} T_{i, j, m}^{z}}
$$

which shows how long masses of water stays in the atmosphere after evaporating and before precipitating down over the South Asian landmass. Here $M$ is the total number of Lagrangian water trajectories, $t^{P}$ is the time when the water trajectories precipitate, $t^{E}$ is the time when they evaporate, and $T_{i, j, m}^{z}$ is the Lagrangian water transport $\left(\mathrm{kg} \mathrm{s}^{-1}\right)$ of the trajectory indexed $m$ through the surface.

The vertically integrated atmospheric water flux was also computed from the Lagrangian trajectories to describe the water transport routes in longitude-latitude coordinates:

$$
\begin{gathered}
F_{i, j}^{x}=\frac{\sum_{k^{\prime}=0}^{k z} \sum_{m} T_{i, j, k^{\prime}, m}^{x}}{\Delta y_{i, j}}, \\
F_{i, j}^{y}=\frac{\sum_{k^{\prime}=0}^{k z} \sum_{m} T_{i, j, k^{\prime}, m}^{y}}{\Delta x_{i, j}} .
\end{gathered}
$$

Here $T_{i, j, k^{\prime}, m}^{x}$ and $T_{i, j, k^{\prime}, m}^{y}$ are the Lagrangian water transports by the trajectory index $m$ through the meridional-vertical 

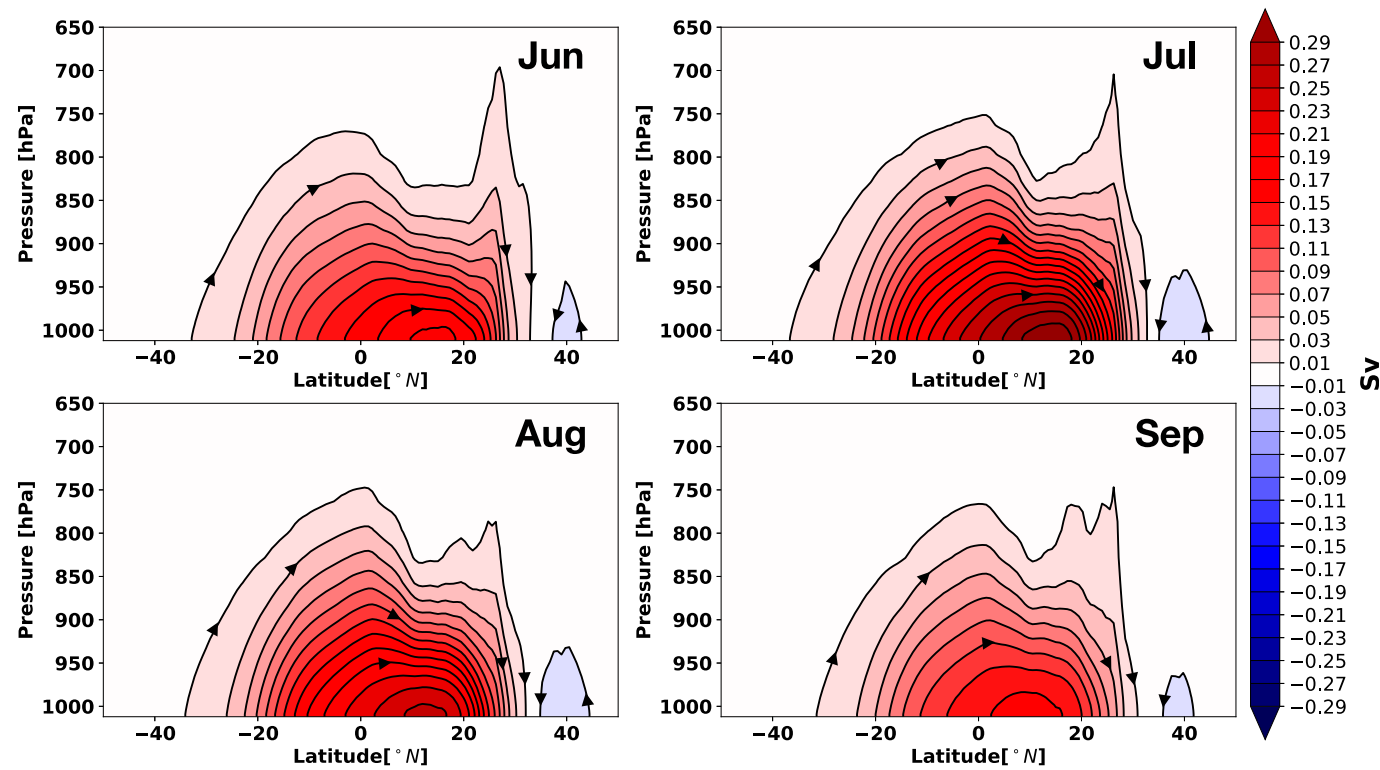

FIG. 2. The meridional Lagrangian water-mass streamfunction (Sv) computed from all the precipitated trajectories over the South Asian landmass for June-September months over the 10-yr study period. The black arrows indicate the direction of the water transport.

and zonal-vertical grid box face respectively. The amplitude of the vertically integrated horizontal water flux is thus

$$
F_{i, j}=\sqrt{\left(F_{i, j}^{x}\right)^{2}+\left(F_{i, j}^{y}\right)^{2}}
$$

which has the unit $\mathrm{kg} \mathrm{s}^{-1} \mathrm{~m}^{-1}$ or $10^{-9} \mathrm{~Sv} \mathrm{~m}^{-1}\left(1 \mathrm{~Sv} \equiv 10^{9} \mathrm{~kg} \mathrm{~s}^{-1}\right)$.

\section{c. Lagrangian study design}

To study the origin of the monsoonal precipitation, we have followed water-mass trajectories backward in time from their precipitation points to their evaporation points. To get a detailed understanding of the monsoonal precipitation, the Lagrangian water-mass parcels over the South Asian landmass were started during the JJAS months every $6 \mathrm{~h}$ for 10 years (2009-18). During the study period there were three summer precipitation deficit years $(2009,2014$, and 2015) and no excessive summer rainfall years over South Asia (Parthasarathy et al. 1995). The atmospheric trajectories were initiated at the surface only when precipitation $(P)$ exceeded evaporation $(E)$ and traced backward until they reached the surface again, where evaporation exceeded precipitation. The trajectories were followed for a maximum of one year. Note that in the present study, the atmospheric water is traced from the net precipitation $(E-P<0)$ to the net evaporation points $(E-P>0)$ and not from the total precipitation to the total evaporation. Thus this should have lead to an underestimation of the total rainfall. However, it was found that the derived net precipitation is higher than the observed total precipitation (Fig. S1 in the online supplemental material). The computation of the vertical mass transport of atmospheric water in the present study [Eq. (6)] omits diffusive moisture transports, specific cloud liquid water, specific cloud ice water, specific rain, and snow water content, thus leading toward an overestimation of the net precipitation as compared to the total precipitation. For instance, an evaporated water parcel during its ascent condenses, forms cloud water, and stays in the atmosphere. This will be added as a sink of atmospheric water in Eq. (6), while the reevaporation of this cloud water will act as a source. The contribution from these sources and sinks will cancel each other if an integration of the $E-P$ values is performed over the period where clouds form and evaporate (Fig. S2) but separation of the net precipitation and net evaporation or $E-P$ integration over very short time periods will lead toward an overestimation [Figs. S1 and S2 (top row)]. Additional reasons might also be related to the diffusive moisture transports, which are omitted, and could transport the water horizontally from high to low moisture regions. This overestimation is more prominent over the Southern Hemispheric westerlies and storm track regions of the Atlantic and Pacific Oceans, and less noticeable over South Asia (Fig. S1).

The contribution of oceanic regions and local recycling to the South Asian summer monsoon precipitation was estimated by selecting five regions as shown in Fig. 1a. The starting positions of the Lagrangian water-mass parcels over the South Asian landmass (land points within $66^{\circ}-$ $\left.99^{\circ} \mathrm{E}, 6.75^{\circ}-39^{\circ} \mathrm{N}\right)$ were denoted as "Local." The ocean basins were termed the Arabian Sea (AS), the Bay of Bengal (BoB), and the central and south Indian Ocean (CSIO). The contribution of the trajectories originating from outside of these regions were classified as "Remote." The local recycling is defined as a combination of processes by which a fraction of the precipitation falls down over a given area due to the evapotranspiration from the same 

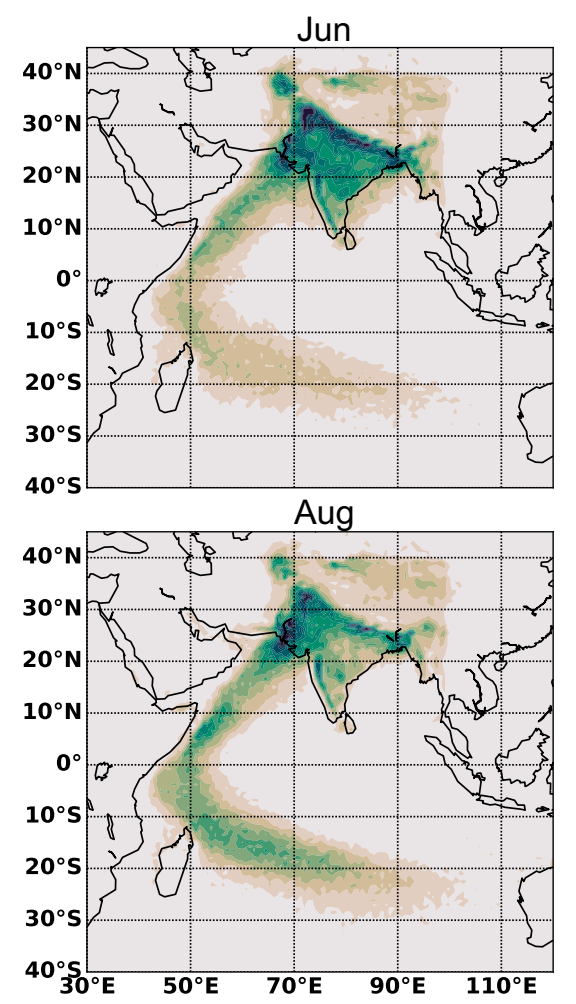
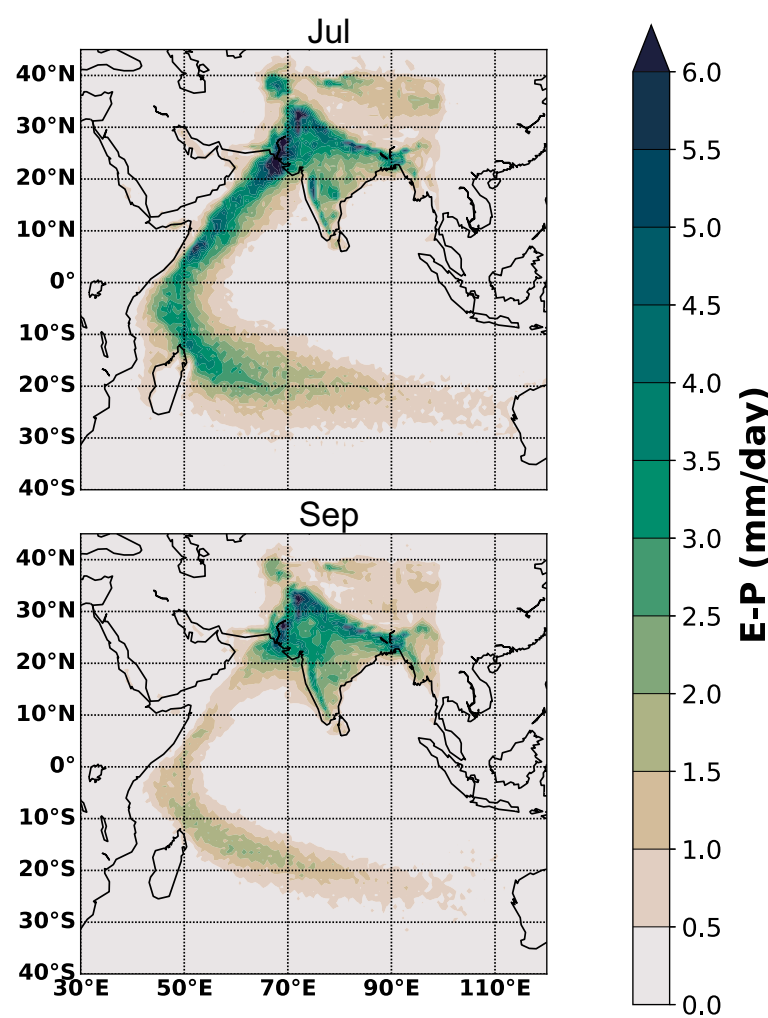

FIG. 3. Net evaporation $\left(\mathrm{mm} \mathrm{day}^{-1}\right)$ computed from the Lagrangian backward water-mass trajectories, which are responsible for net precipitation over the South Asian landmass during June-September.

area. In the present study, this area is the region denoted as Local (Fig. 1a).

\section{Results}

The atmospheric water that precipitates over the South Asian landmass tends to follow the Somali low-level jet as shown by the representative trajectories in Fig. 1. To quantify the atmospheric water transport and its pathways in the meridional-vertical plane, a Lagrangian overturning watermass streamfunction was calculated using Eq. (7) and is presented in Fig. 2. The atmospheric freshwater streamlines represent the average atmospheric water transport pathway and do not necessarily follow the same path as an individual water trajectory would take. Note that the streamlines are starting at the surface where evaporation exceeds precipitation and terminating over the surface of the South Asian landmass where the opposite holds true. The results revealed that most of the atmospheric water that arrives at the South Asian landmass as precipitation is transported at levels below $650 \mathrm{hPa}$. The meridional water transport (Fig. 2) starts to increase from the month of June and reaches its peak by July $(\approx 0.30 \mathrm{~Sv}$. Then it starts to reduce by August and onward. Note that in each summer monsoon month there is a steep downward streamline around $30^{\circ} \mathrm{N}$. This indicates an abrupt blocking of the atmospheric water transport around this latitude, which could be explained by the Himalayan mountain belt.
The Lagrangian backward-tracking simulation enabled us to locate the water source regions during June to September over the 10-yr study period (Fig. 3). The strongest signature of the evaporative sources was identified during the month of July and it starts to decay by August, which continues till September. During the peak monsoon months of July and August, the central and south Indian Ocean provide most of the waters $(43 \%, 40 \%)$, which is then followed by local recycling $(27 \%, 31 \%)$, the Arabian Sea $(16 \%, 14 \%)$, remote sources, and the Bay of Bengal (see Table 1 for exact values). In June and September, local recycling processes become the highest contributor. The atmospheric water percentage originating from the Bay of Bengal is always minimal with respect to remaining source areas. The results further indicate that the local recycled precipitation attains its maximum value in June $(\approx 0.20 \mathrm{~Sv}$; achieved by summing the net precipitation transports due to the local evaporative sources) and minimum in September $(\approx 0.16 \mathrm{~Sv})$. Although the local recycled precipitation reaches its lowest value in September, its contribution to the total rainfall remained higher (39\%; Table 1) due to the relatively lower contribution from other sources. However, a previous study by Pathak et al. (2014) reported that in September the highest contribution by the local recycled rainfall to the South Asian precipitation is due to the enhanced evapotranspiration. This dissimilarity might be related to the use of a 2D moisture tracing model by Pathak et al. (2014) in which the effect of the directional vertical wind shear is absent. 
TABLE 1. Atmospheric water transport ( Sv) from different regions to the South Asian landmass. The contribution (\%) of the various defined sectors to the South Asian summer rainfall and the residence time (days) of the atmospheric water sourced from those regions is provided in the parentheses. CSIO = central and south Indian Ocean; AS = Arabian Sea; BoB = Bay of Bengal.

\begin{tabular}{lllll}
\hline \hline Regions & \multicolumn{1}{c}{ June } & \multicolumn{1}{c}{ July } & \multicolumn{1}{c}{ August } & \multicolumn{1}{c}{ September } \\
\hline CSIO & $0.16 \mathrm{~Sv}(31 \%, 17$ days $)$ & $0.27 \mathrm{~Sv}(43 \%, 15$ days $)$ & $0.22 \mathrm{~Sv}(40 \%, 18$ days $)$ & $0.14 \mathrm{~Sv}(33 \%, 21 \mathrm{days})$ \\
Local & $0.20 \mathrm{~Sv}(39 \%, 2$ days $)$ & $0.17 \mathrm{~Sv}(27 \%, 2$ days $)$ & $0.17 \mathrm{~Sv}(31 \%, 2$ days $)$ & $0.16 \mathrm{~Sv}(39 \%, 3 \mathrm{days})$ \\
AS & $0.08 \mathrm{~Sv}(15 \%, 7$ days $)$ & $0.10 \mathrm{~Sv}(16 \%, 6$ days $)$ & $0.07 \mathrm{~Sv}(14 \%, 8$ days $)$ & $0.05 \mathrm{~Sv}(11 \%, 10 \mathrm{days})$ \\
BoB & $0.02 \mathrm{~Sv}(5 \%, 3$ days $)$ & $0.01 \mathrm{~Sv}(2 \%, 3$ days $)$ & $0.01 \mathrm{~Sv}(2 \%, 3$ days $)$ & $0.01 \mathrm{~Sv}(3 \%, 2 \mathrm{days})$ \\
Remote & $0.05 \mathrm{~Sv}(10 \%, 41$ days $)$ & $0.08 \mathrm{~Sv}(12 \%, 41$ days $)$ & $0.07 \mathrm{~Sv}(13 \%, 44$ days $)$ & $0.06 \mathrm{~Sv}(14 \%, 48$ days $)$ \\
\hline
\end{tabular}

The residence time of the atmospheric water was mapped at the evaporation points using Eq. (8) and is presented in Fig. 4. Note that the residence times of the evaporated water from the defined Remote sources were omitted in Fig. 4 in order to focus on the primary evaporative sources of the South Asian summer monsoon precipitation, although these sources were taken into account while quantifying the spatial average residence time in Table 1. It is evident that the increased transport of atmospheric water from the CSIO during the month of July $(0.27 \mathrm{~Sv})$ as compared to June $(0.16 \mathrm{~Sv})$ is accompanied by a reduction in the residence time (from 17 days in June to 15 days in July; Table 1). This reduced time indicates a probable strengthening of the atmospheric flow that carries the water from the CSIO to the landmass. The increase in the atmospheric flow could further act as an agent to enhance the evaporation if the air parcel above the CSIO is relatively dry due to the strong sweeping of the atmospheric water from that region. The residence time of the evaporated water from the CSIO starts to increase again from August (18 days) and continues until September (21 days), illustrating a possible weakening of the atmospheric water flow to the landmass, and might be one of the contributing factors responsible for reduction in the water transport during those months ( $0.22 \mathrm{~Sv}$ in August and $0.14 \mathrm{~Sv}$ in September; Table 1). The other possibility could be that the majority of the atmospheric water transport from the CSIO is heading toward other sectors and not precipitating down over the South Asian landmass. A similar pattern in the atmospheric water transport and residence time can be seen
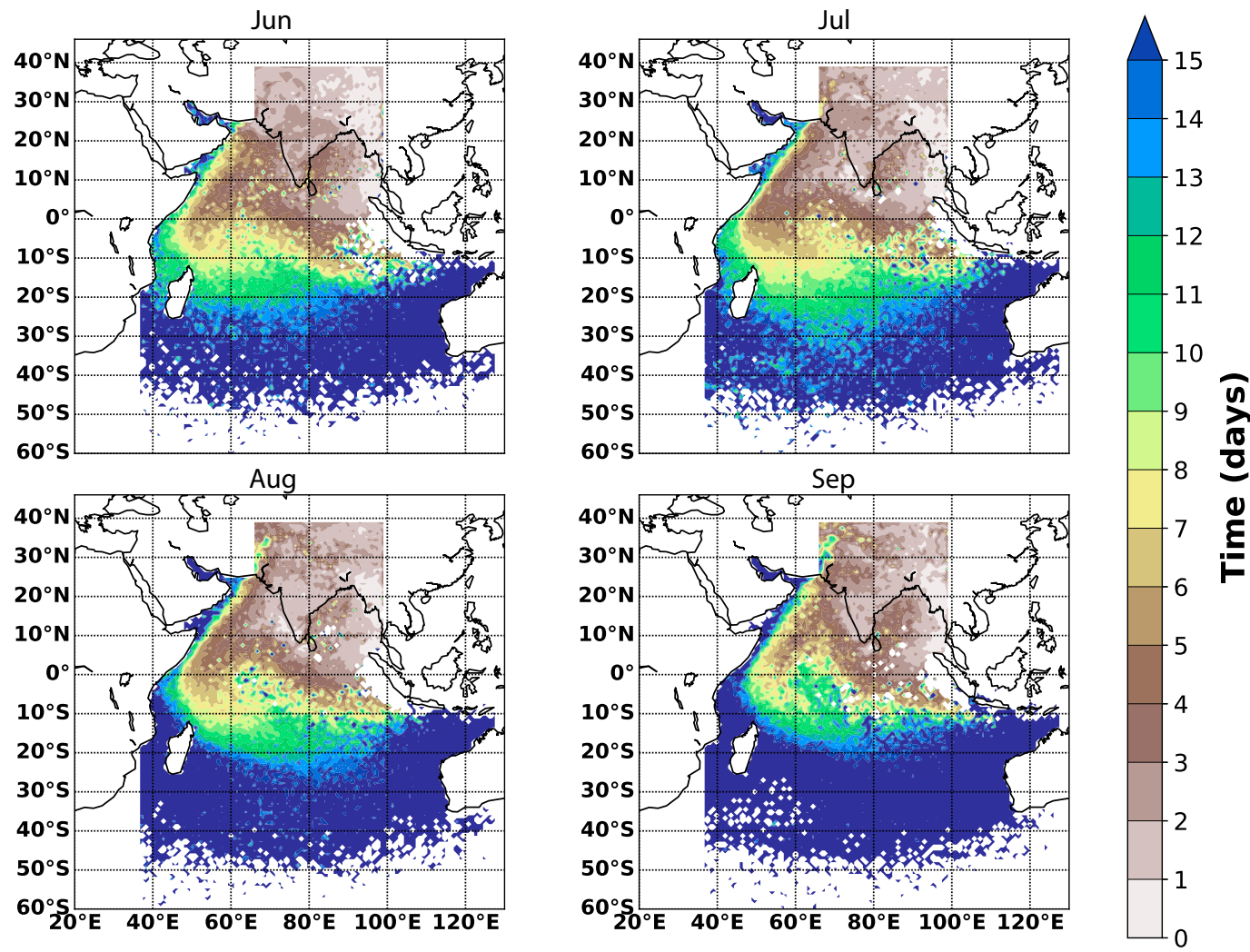

FIG. 4. The residence time (days) of the atmospheric masses of water that have precipitated over the South Asian landmass during June-September. The defined Remote region was excluded here in order to focus on the primary sources of the precipitation. 

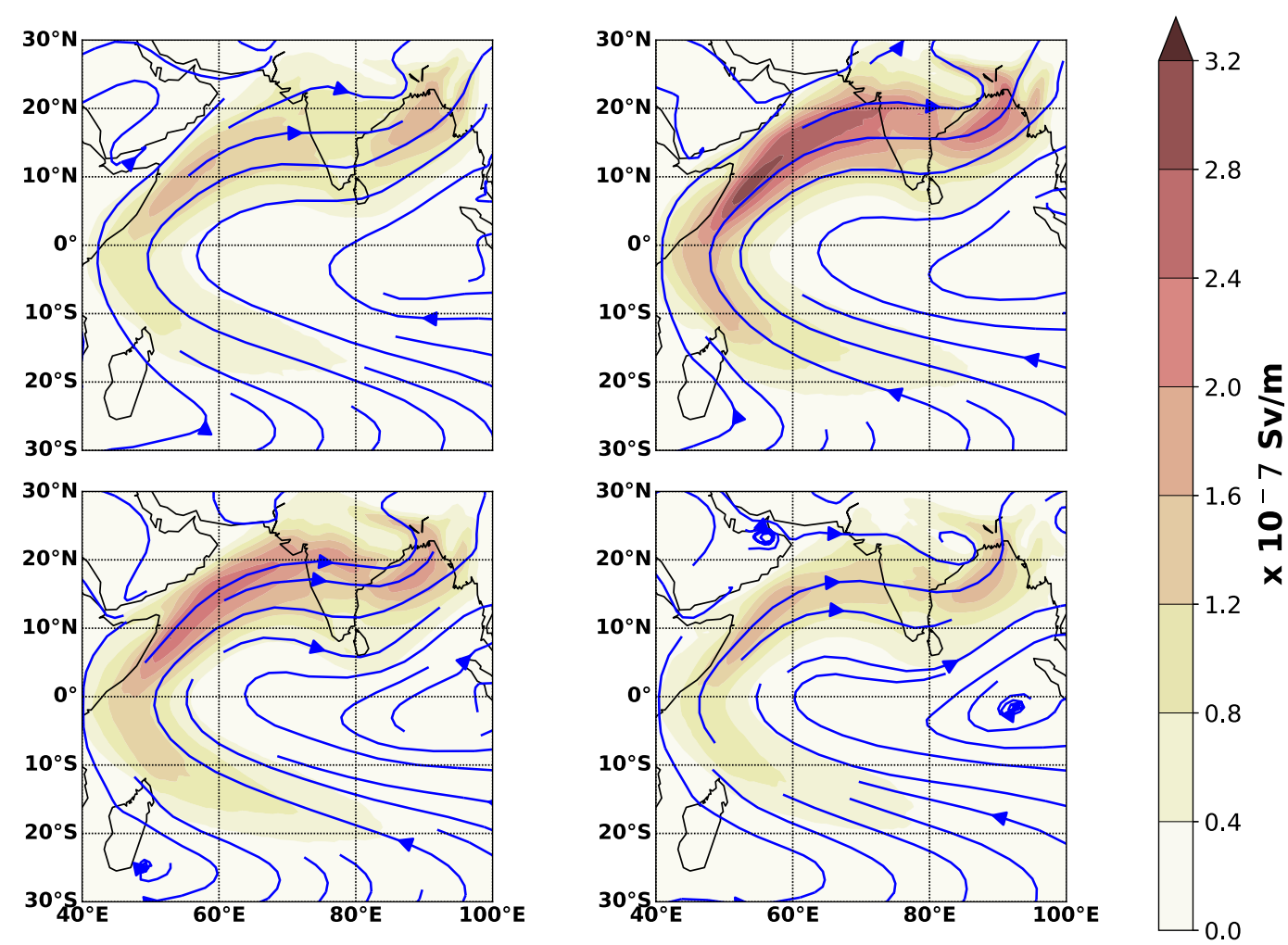

FIG. 5. The vertically integrated horizontal water flux (shaded; $\mathrm{Sv} \mathrm{m}^{-1}$ ) computed from all the Lagrangian water-mass trajectories that have precipitated over the South Asian landmass during June-September. The flux directions are given by the blue lines.

for the Arabian Sea case during June to September (Table 1). The Arabian Sea and the CSIO are linked through the Somali low-level jet (northern branch of the cross-equatorial flow) during the monsoon months (Fig. 1c) and thus it can be speculated that the variation in the contribution from these sources during June to September is related to the strength of this flow to a certain extent. It is noteworthy that the residence time map in Fig. 4 closely resembles with the strength of the Somali lowlevel jet during the monsoon months. This flow reaches its peak strength in July (thus reduced residence time) and deceasing afterward (higher residence time). The residence time of the evaporated waters from the South Asian landmass is found to be very short ( $\sim 2$ days) and pointing toward a rapid recycled precipitation time scale. The $\mathrm{BoB}$ waters that are responsible for the monsoonal precipitation over South Asia stay around 3 days in the atmosphere, whereas it is more than a month for the waters evaporated from remote sources.

In addition to the identification of the atmospheric water origin, it is also beneficial to have knowledge of the actual water transport routes. To infer the atmospheric water pathways, information about only water source regions can sometime be misleading. Evaporative source areas responsible for the summer rainfall cannot provide the pathways of the water transport. To achieve this, we have calculated the vertically integrated horizontal water fluxes using Eq. (11), which is presented in Fig. 5. The results show that there are two regions with strong fluxes $\left(>1.5 \times 10^{-7} \mathrm{~Sv} \mathrm{~m}^{-1}\right)$. The first one is along the Somali coast and over the Arabian Sea, which clearly resembles the Somali low-level jet, and the second region is over the Bay of Bengal. This result is quite interesting in the sense that even though the flux values are higher, there is only a very small contribution of the water originating from the BoB to the South Asian summer rainfall. Thus, the share of the Bay of Bengal to the summer precipitation is indirect. It helps atmospheric waters traveling from other regions by providing a pathway.

The question is thus from where this water originates (evaporates) and precipitates if it is only passing over the BoB. Figure 6 shows the final destination (precipitation region) of the water-mass parcels that have traveled at least once over the BoB. During the monsoon months of June to September the spatial pattern of the precipitation shows little month-tomonth variability. The precipitation is heavily concentrated over the coastal regions of the Ganges-Brahmaputra-Meghna (GBM) Delta, northeast India, and the Myanmar region. In July and August, the precipitating region extends slightly toward the foothills of Himalaya. Figure 7 depicts the location of all the evaporative water sources that have crossed over the BoB at least once and precipitated over the South Asian landmass as shown by Fig. 6.

This shows that there is a small region in the northern part of BoB with strong evaporation. This water is, however, not traveling far but precipitates in the nearby coastal region (not shown by the figures). 

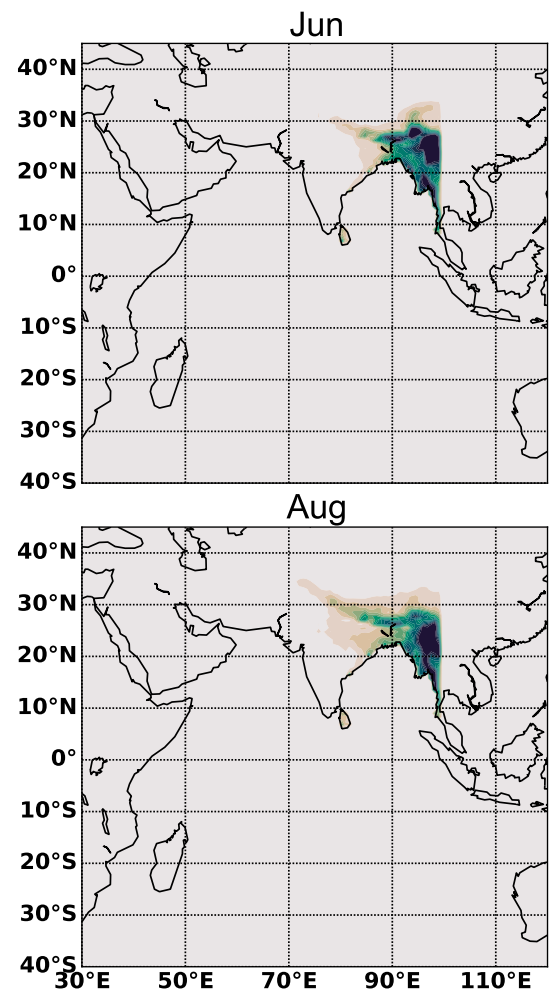
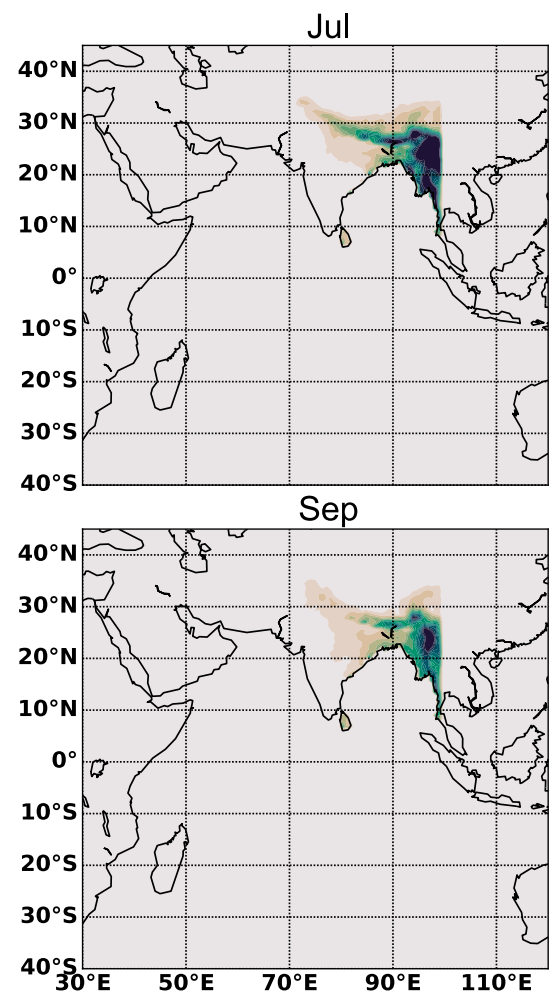

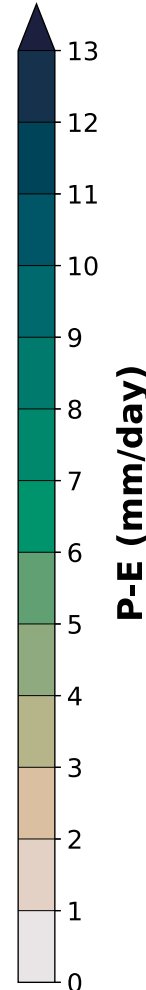

13 12

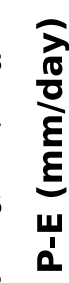

FIG. 6. Net precipitation $\left(\mathrm{mm} \mathrm{day}^{-1}\right)$ computed from Lagrangian water-mass trajectories that have crossed over the Bay of Bengal at least once and fallen over the South Asian landmass.

The heavy rainfall over Myanmar and its nearby regions from June to September (Fig. 6) is thus primarily fed by the waters originating from the central and south Indian Ocean, which have passed over the BoB (Fig. 7). The percentage contribution of each specific basin to the South Asian summer rainfall, when atmospheric water pass over the Bay of Bengal is summarized in Table 2. It indicates that more than $50 \%$ of the net precipitation that crosses over the $\mathrm{BoB}$ is primarily originating from the CSIO.

The role of each specific region for the spatial precipitation variability over the South Asian landmass was estimated by selecting backward trajectories terminating over these locations (Fig. 8). The CSIO provides most of the rainfall over the coastal regions of the GBM Delta, northeast India, Myanmar, the foothills of the Himalayas, and the southwestern coast of India during the months from June to September. The precipitation over most of these locations can be attributed to the BoB pathway. This is because we have shown that more than half of the net precipitation that crosses over the BoB is primarily originating from the CSIO and fallen down over these locations. During the peak monsoon months of July and August, the CSIO also contributes to the precipitation over central-east India. Thus the central-east Indian precipitation must have arrived from some other pathways and not via the BoB pathway. The evaporated water from the AS gives rainfall mostly over the western coast of India throughout June-September. In July and August, it also provides rainfall over west-central India.
The sharing from the local source is spatially invariable during the four monsoon months. It generally provides precipitation over the Indo-Gangetic plain. Note that the contribution of the local recycling to the precipitation over the western coast of India is almost nonexistent. This is probably due to the fact that most of the evaporated water from the western cost of India is pushed outside of the South Asian landmass by the prevailing westerly flow [see Fig. 8 in Pathak et al. (2014)].

The interannual variability of the precipitation over the South Asian landmass was studied by decomposing it depending on its origin. This was achieved by summing the mass transports of the water trajectories sourced from specific regions and precipitated over the South Asian landmass between the years 2009 and 2018 as shown by Fig. 9. Most of the total interannual variability is found to be due to the nonlocal sources (i.e., water originating from outside the South Asian landmass). The majority of this nonlocal variability is primarily determined by the water originating from the CSIO. The local recycling variability shows a rather different pattern than the nonlocal with an almost constant value from 2010 to 2013 and a smooth increase from 2013 and onward. The contributions from the Arabian Sea, the Bay of Bengal, and remote sources to the interannual precipitation variability are small. The year-to-year atmospheric water residence time analysis was found to be inadequate to explain the reported interannual precipitation variation over South Asia (Fig. S3), unlike the month-to-month rainfall variability. 

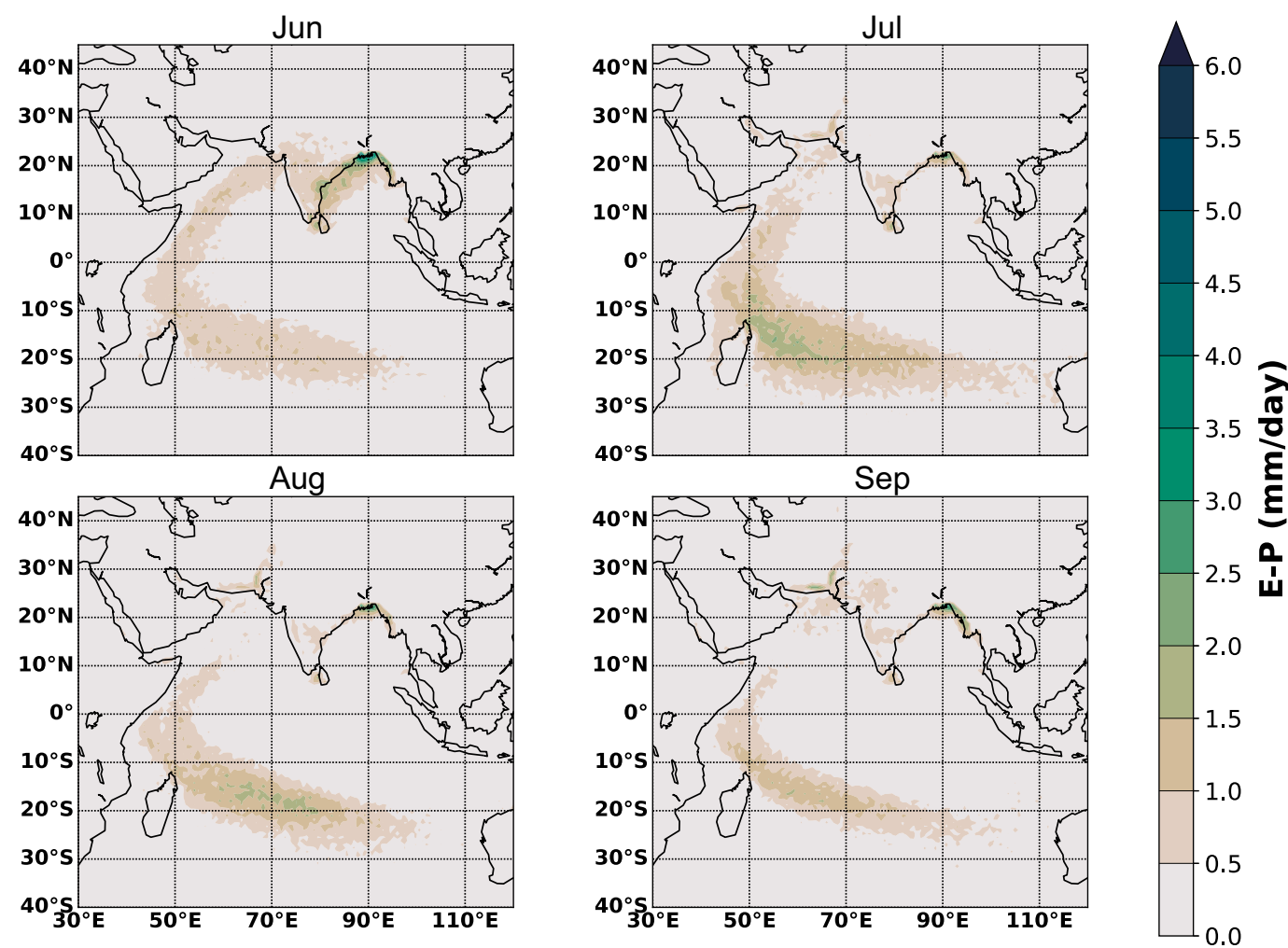

FIG. 7. Net evaporation $\left(\mathrm{mm} \mathrm{day}^{-1}\right.$ ) computed from Lagrangian water-mass trajectories that have crossed over the Bay of Bengal at least once and are responsible for precipitation over the South Asian landmass.

\section{Discussion and conclusions}

Identification of the water sources and their role with regard to summer monsoon precipitation variability over the South Asian landmass has been investigated using atmospheric water-mass trajectories. These trajectories were computed using a new water-mass conservation method, which makes it possible to trace the atmospheric water backward from the net precipitation to the net evaporation surfaces. By doing so, we were able to calculate the contributions of different ocean and land regions to the total South Asian summer monsoon precipitation. The results indicate that the evaporated waters from the central and south Indian Ocean are the major contributor to the South Asian summer monsoon precipitation, followed by contributions from the local recycling, the Arabian Sea, remote sources (outside of the studied domain), and the Bay of Bengal, in agreement with the earlier studies (Mei et al. 2015; Pathak et al. 2017b). In contrary, using water vapor tracers in a 3D atmospheric model Bosilovich and Schubert (2002) found that the west oceanic region (approximately same as the Arabian Sea in our case) was the primary contributor to the South Asian monsoon precipitation. Although the contribution of the atmospheric waters originating from the Bay of Bengal was found to be small, the Lagrangian trajectories revealed that it allows waters from the other regions to cross over it. It was also shown that this Bay of Bengal pathway is mostly used by the waters originating from the central and south Indian Ocean, which were then precipitated over the coastal regions of the
GBM Delta, northeast India, Myanmar, and the foothills of the Himalayas. The atmospheric trajectory analysis further revealed that when waters from the central and south Indian Ocean are not traveling through the BoB pathway, they provide rainfall over central-east India during the months of July and August. Atmospheric waters from the Arabian Sea were found to be responsible for precipitation over the western coast of India during the summer monsoon months. In July and August, it also extends from the western coast to the interior of the Indian subcontinent. Summer precipitation due to local recycling was estimated to be spatially invariable, mainly confined to the Indo-Gangetic plain. The strength of the recycled precipitation although changes, reaching its maximum value in June and minimum in September. It was also found that the percentage contribution from the local recycled precipitation to the monsoonal rainfall remained higher in September despite its lower strength. This is due to relatively

TABLE 2. Contribution of the different regions to the South Asian summer rainfall when the atmospheric water passes through the Bay of Bengal (\%). CSIO = central and south Indian Ocean; AS $=$ Arabian Sea; BoB = Bay of Bengal.

\begin{tabular}{lcrrr}
\hline \hline Regions & Jun & Jul & Aug & Sep \\
\hline CSIO & 57 & 67 & 64 & 56 \\
AS & 11 & 7 & 6 & 8 \\
BoB & 11 & 4 & 5 & 6 \\
\hline
\end{tabular}




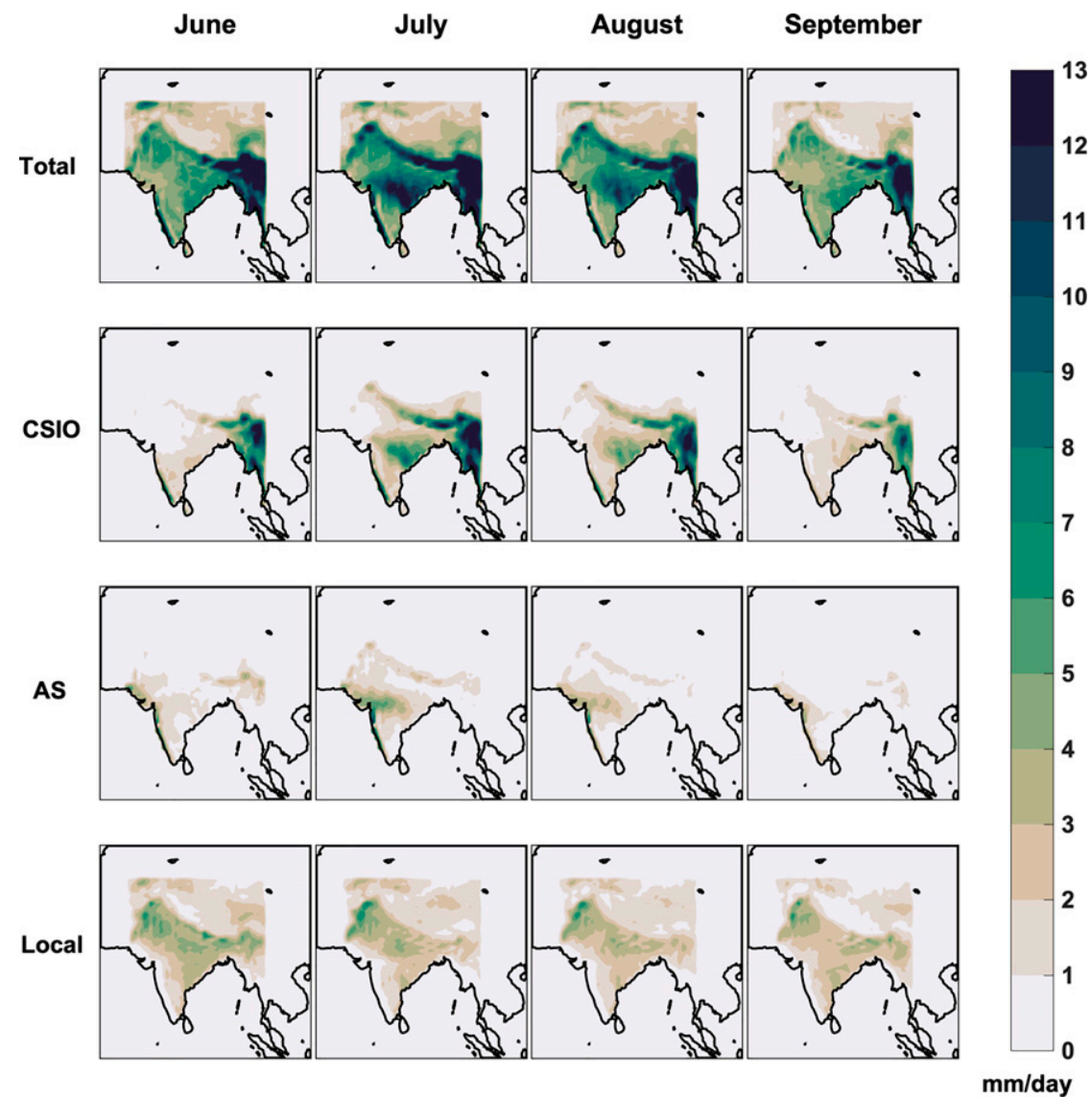

FIG. 8. (top) Total net precipitation $\left(\mathrm{mm} \mathrm{day}^{-1}\right)$ for the months of June-September. In addition, monthly mean net precipitation over the South Asian landmass due to the evaporated water sourced from (second row) the central and south Indian Ocean (CSIO), (third row) the Arabian Sea (AS), and (bottom) the Local region.

smaller contributions from the other sources and not associated with the higher amount of evapotranspiration as suggested by Pathak et al. (2014). Precipitation due to the local recycling processes was found to be negligible along the western coast of India (Western Ghats) and might be attributed to the prevailing westerly flow. The reported spatial distribution and quantification of the local recycled precipitation might vary if irrigation is included in the ERA-Interim reanalysis dataset. Irrigation enhances the transpiration from the land and thus also the atmospheric humidity (Tuinenburg and de Vries 2017). Based on sensitivity experiments using a coupled atmosphere-land model Devanand et al. (2019) demonstrated that realistic representation of the irrigation process helps to increase the rainfall during the month of September over north-northwest India. It is important to mention that the present study deals with the identification of the water sources that are responsible only for the South Asian rainfall during JJAS months between 2009 and 2018 and does not separate the short periods ( 3 days) of anomalously high (active) and low (break) precipitation. Thus the prominent intraseasonal Indian monsoon features, namely a north-south asymmetry in precipitation anomaly from the Indian subcontinent to the Indian
Ocean and an east-west imbalance from the central part of India to the eastern Indian landmass (Pathak et al. 2017a), will not be separable here. The investigation of the evaporative transports and atmospheric water residence time at the defined regions leads to the speculation that the month-to-month precipitation variability to a certain extent is associated with the Somali low-level jet that carries water to the landmass.

The Lagrangian analysis of the year-to-year precipitation indicated that the local recycled precipitation has increased since 2013. The role of the Arabian Sea, remote sources, and the Bay of Bengal to the interannual variability of the South Asian summer rainfall was found to be small. The interannual precipitation variation over the South Asian landmass was found to be mainly controlled by the atmospheric waters originating and traveling from the central and southern Indian Ocean. This variability of the atmospheric water transport is either caused by the interannual variation of the evaporation over the central and south Indian Ocean and/or due to the year-to-year fluctuations of the winds that advect the water toward the landmass. Thus a continuation of the present study could be to trace the atmospheric water with Lagrangian trajectories starting from the evaporation areas over the central 


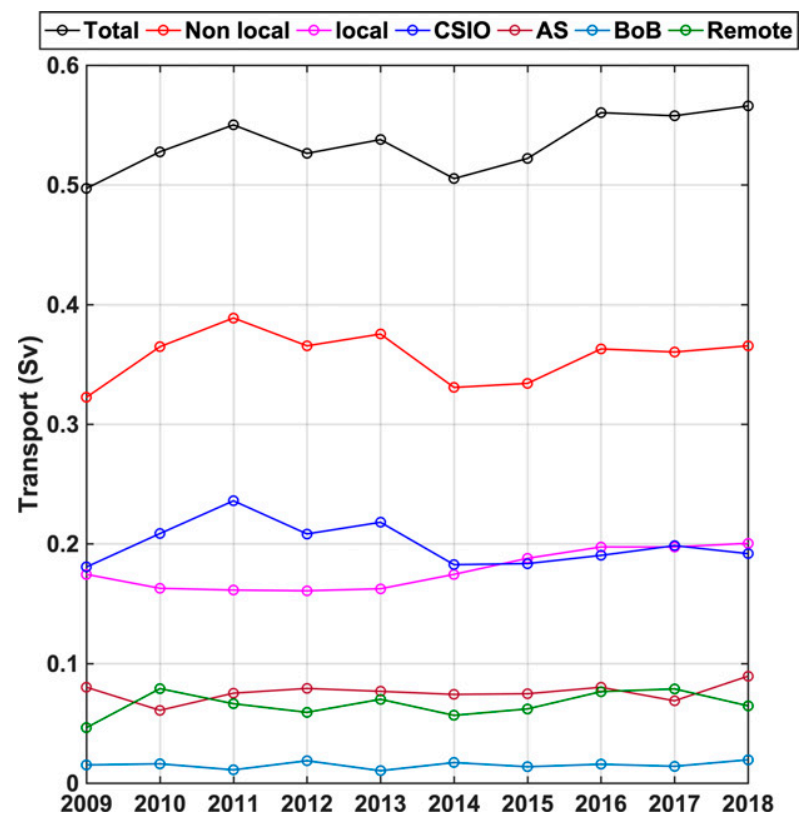

FIG. 9. The interannual variability of the precipitation (Sv) integrated over the South Asian landmass (black) during JuneSeptember due to nonlocal sources (red line), Local (magenta line), central and south Indian Ocean (CSIO; blue line), Arabian Sea (AS; bright red), Bay of Bengal (BoB; navy blue), and remote sources (green line).

and south Indian Ocean and follow them until they precipitate, in order to quantify the relative importance of these two effects. Also it would be interesting to understand the effects of the chosen time period and of horizontal, vertical, and temporal resolution on the results reported in the present study. In this regard it is important to mention that an Eulerian study based on the JJAS horizontal moisture flux decomposition indicated the domination of the dynamic component (circulation variability) over the thermodynamic component (moisture variation) in order to explain the interannual summer monsoon variability over South Asia (Walker et al. 2015). The atmospheric water residence time analysis is found to be insufficient to explain the reported year-to-year precipitation variation (Fig. S3), unlike the month-to-month rainfall variability. It should be noted that the residence time does not always represent the strength of the flow. Consider a hypothetical situation in which the South Asian landmass experienced an excess and a deficit rainfall year consecutively. The results from the hypothetical case revealed that during those two years the total evaporation over the CSIO remained the same but during the deficit year majority of water was transported by the winds to some other region. In this case the comparison of the atmospheric water residence time will be inconclusive to explain the variability of the flow as the major portion of the water transport completely changed its direction. The lowest precipitation was noticed in 2009, 2014, and 2015, of which 2009 and 2015 are El Niño-Southern Oscillation (ENSO) years. The interannual rainfall variation over South Asia is believed to be strongly associated with ENSO (Pant and Parthasarathy 1981;
Rasmusson and Carpenter 1982) and weakly with the Indian Ocean dipole (IOD) (Ashok et al. 2004; Cherchi and Navarra 2013) and snow cover over Eurasia and the Tibetan Plateau (Blanford 1884; Hahn and Shukla 1976). However, ENSO cannot not explain more than half of the observed interannual variability (Webster et al. 1998) and a relatively new mode known as the equatorial Indian Ocean oscillation (EQUINOO) emerges as a contributing factor (Gadgil et al. 2004). The influence of the ENSO, IOD, snow cover, and EQUINOO on the year-to-year precipitation variability over South Asia has not been studied here and lies outside the scope of the present study.

The current research is not just restricted to identification of the atmospheric water sources and their percentage contribution to the South Asian monsoon rainfall but goes beyond that. There are large uncertainties looming over the role of the Bay of Bengal to the South Asian summer precipitation. Previous studies (Pathak et al. 2017b; Mei et al. 2015; Bosilovich and Schubert 2002) and also the present analyses revealed that the Bay of Bengal only provides $3 \%-4 \%$ of the total summer rainfall over South Asia. However, Yoon and Chen (2005) found that the monsoon depressions over the Bay of Bengal responsible for $45 \%-55 \%$ of the total summer rainfall. These results indicate that the masses of water in the monsoon depressions must have been originated from somewhere else. The 3D novel Lagrangian approach used in the present study made it possible to find an answer to this question. The atmospheric water-mass trajectory analyses revealed that the Bay of Bengal indirectly contributes to the South Asian summer monsoon rainfall by providing its path primarily to the masses of water originating from the CSIO. Additionally, the analyses provided the transport time scales that state how long the evaporative water from the South Asian landmass, the central and south Indian Ocean, the Arabian Sea, and the Bay of Bengal stays in the atmosphere before precipitating down over various sectors of South Asia during the June to September months. For instance, in the month of July it was found that the evaporative water from the AS takes on an average 6 days to reach west-central India. This connection from the evaporation-toprecipitation regions and the transport time scales could significantly improve accuracy and predictability of the month-to-month summer rainfall forecast for the different South Asian sectors.

Acknowledgments. The authors wish to acknowledge Peter Lundberg for his constructive comments. In addition, the discussions with Sara Berglund and Aitor Aldama Campino on this work were highly valued and appreciated. A special gratitude to Dr. Roxy Mathew Koll, a climate scientist at the Indian Institute of Tropical Meteorology, Pune, for his enthusiastic query about the air and atmospheric water circulation over the Indian subcontinent at the Ocean Sciences meeting 2020 in San Diego, which partially lead to the computation of the meridional water-mass stream function in the present study. The TRACMASS trajectory model can be downloaded from https:/github.com/TRACMASS. The TRACMASS model integrations and the Lagrangian trajectory computations were performed on resources provided by the Swedish National Infrastructure for Computing (SNIC) at the National 
Supercomputer Centre (NSC) partially funded by the Swedish Research Council through Grant Agreement 2016-07213. No potential conflict of interest was reported by the authors.

Data availability statement. The ERA-Interim data used in the present study are freely available from the ECMWF (https:/www.ecmwf.int/en/forecasts/datasets/archive-datasets/ reanalysis-datasets/era-interim). The Lagrangian trajectory model TRACMASS outputs are freely available at http://doi.org/ 10.5281/zenodo.4322390. The analysis scripts are available on request from the corresponding author.

\section{REFERENCES}

Ashok, K., Z. Guan, N. Saji, and T. Yamagata, 2004: Individual and combined influences of ENSO and the Indian Ocean dipole on the Indian summer monsoon. J. Climate, 17, 3141-3155, https://doi.org/10.1175/1520-0442(2004)017<3141:IACIOE > 2.0.CO;2.

Blanford, H. F., 1884: II. On the connexion of the Himalaya snowfall with dry winds and seasons of drought in India. Proc. Roy. Soc. London, 37, 3-22, https://doi.org/10.1098/ rspl.1884.0003.

Blanke, B., M. Arhan, G. Madec, and S. Roche, 1999: Warm water paths in the equatorial Atlantic as diagnosed with a general circulation model. J. Phys. Oceanogr., 29, 2753-2768, https:// doi.org/10.1175/1520-0485(1999)029<2753:WWPITE>2.0.CO;2.

Bosilovich, M. G., and S. D. Schubert, 2002: Water vapor tracers as diagnostics of the regional hydrologic cycle. J. Hydrometeor., 3, 149-165, https://doi.org/10.1175/1525-7541(2002)003<0149: WVTADO $>2.0 . \mathrm{CO} ; 2$.

Cherchi, A., and A. Navarra, 2013: Influence of ENSO and of the Indian Ocean dipole on the Indian summer monsoon variability. Climate Dyn., 41, 81-103, https://doi.org/10.1007/s00382012-1602-y.

Christensen, J. H., and Coauthors, 2013: Climate phenomena and their relevance for future regional climate change. Climate Change 2013: The Physical Science Basis, T. F. Stocker et al., Eds., Cambridge University Press, 1217-1308.

Dee, D. P., and Coauthors, 2011: The ERA-Interim reanalysis: Configuration and performance of the data assimilation system. Quart. J. Roy. Meteor. Soc., 137, 553-597, https://doi.org/ 10.1002/qj.828.

Devanand, A., M. Huang, M. Ashfaq, B. Barik, and S. Ghosh, 2019: Choice of irrigation water management practice affects Indian summer monsoon rainfall and its extremes. Geophys. Res. Lett., 46, 9126-9135, https://doi.org/10.1029/2019GL083875.

Dey, D., and K. Döös, 2019: The coupled ocean-atmosphere hydrologic cycle. Tellus, 71A, 1650413, https://doi.org/10.1080/ 16000870.2019.1650413.

—, and —, 2020: Atmospheric freshwater transport from the Atlantic to the Pacific Ocean: A Lagrangian analysis. Geophys. Res. Lett., 47, e2019GL086176, https://doi.org/10.1029/ 2019GL086176.

Döös, K., 1995: Interocean exchange of water masses. J. Geophys. Res. Oceans, 100, 13 499-13 514, https://doi.org/10.1029/95JC00337.

— J. Jycander, and A. C. Coward, 2008: Lagrangian decomposition of the Deacon cell. J. Geophys. Res. Oceans, 113, C07028, https://doi.org/10.1029/2007JC004351.

__ B. Jönsson, and J. Kjellsson, 2017: Evaluation of oceanic and atmospheric trajectory schemes in the TRACMASS trajectory model v6.0. Geosci. Model Dev., 10,1733-1749, https://doi.org/ 10.5194/gmd-10-1733-2017.
Gadgil, S., and K. R. Kumar, 2006: The Asian monsoonAgriculture and economy. The Asian Monsoon, B. Wang, Ed., Springer, 651-683.

—, P. Vinayachandran, P. Francis, and S. Gadgil, 2004: Extremes of the Indian summer monsoon rainfall, ENSO and equatorial Indian Ocean oscillation. Geophys. Res. Lett., 31, L12213, https://doi.org/10.1029/2004GL019733.

Gimeno, L., A. Drumond, R. Nieto, R. M. Trigo, and A. Stohl, 2010: On the origin of continental precipitation. Geophys. Res. Lett., 37, L13804, https://doi.org/10.1029/2010GL043712.

Goessling, H., and C. Reick, 2012: Atmospheric water vapour tracers and the significance of the vertical dimension. Atmos. Chem. Phys. Discuss., 12, 30119-30 176, https://doi.org/10.5194/ acpd-12-30119-2012.

Hahn, D. G., and J. Shukla, 1976: An apparent relationship between Eurasian snow cover and Indian monsoon rainfall. J. Atmos. Sci., 33, 2461-2462, https://doi.org/10.1175/15200469(1976)033<2461:AARBES>2.0.CO;2.

Hersbach, H., and Coauthors, 2020: The ERA5 global reanalysis. Quart. J. Roy. Meteor. Soc., 146, 1999-2049, https://doi.org/ 10.1002/qj.3803.

Kjellsson, J., and K. Döös, 2012: Lagrangian decomposition of the Hadley and Ferrel cells. Geophys. Res. Lett., 39, L15807, https://doi.org/10.1029/2012GL052420.

Martinez, J. A., and F. Dominguez, 2014: Sources of atmospheric moisture for the La Plata River basin. J. Climate, 27, 67376753, https://doi.org/10.1175/JCLI-D-14-00022.1.

Mei, R., M. Ashfaq, D. Rastogi, L. R. Leung, and F. Dominguez, 2015: Dominating controls for wetter South Asian summer monsoon in the twenty-first century. J. Climate, 28, 3400-3419, https://doi.org/10.1175/JCLI-D-14-00355.1.

Ordóñez, P., P. Ribera, D. Gallego, and C. Peña-Ortiz, 2012: Major moisture sources for western and southern India and their role on synoptic-scale rainfall events. Hydrol. Processes, 26, 38863895, https://doi.org/10.1002/hyp.8455.

Pant, G., and S. B. Parthasarathy, 1981: Some aspects of an association between the southern oscillation and Indian summer monsoon. Arch. Meteor. Geophys. Bioclimatol., 29B, 245-252, https://doi.org/10.1007/BF02263246.

Parthasarathy, B., A. A. Munot, and D. R. Kothawale, 1995: Monthly and seasonal rainfall series for all India, homogeneous regions and meteorological subdivisions: 1871-1994, Research Rep. RR-065, Indian Institute of Tropical Meteorology, 113 pp., http://www.tropmet.res.in/ lip/Publication/RR-pdf/RR65.pdf.

Pathak, A., S. Ghosh, and P. Kumar, 2014: Precipitation recycling in the Indian subcontinent during summer monsoon. J. Hydrometeor., 15, 2050-2066, https://doi.org/10.1175/JHM-D-13-0172.1.

,,--- , and R. Murtugudde, 2017a: Role of oceanic and terrestrial atmospheric moisture sources in intraseasonal variability of Indian summer monsoon rainfall. Sci. Rep., 7, 12729, https://doi.org/10.1038/s41598-017-13115-7.

$\longrightarrow,-$ J. A. Martinez, F. Dominguez, and P. Kumar, 2017b: Role of oceanic and land moisture sources and transport in the seasonal and interannual variability of summer monsoon in India. J. Climate, 30, 1839-1859, https://doi.org/10.1175/JCLID-16-0156.1.

Pisharoty, P., 1965: Evaporation from the Arabian Sea and the Indian southwest monsoon. Proc. Symp. Meteorological Results of the International Indian Ocean Expedition, Bombay, India, India Meteorological Department, 43-54.

Rasmusson, E. M., and T. H. Carpenter, 1982: Variations in tropical sea surface temperature and surface wind fields associated 
with the southern oscillation/El Niño. Mon. Wea. Rev., 110, 354-384, https://doi.org/10.1175/1520-0493(1982)110<0354: VITSST $>2.0 . \mathrm{CO} ; 2$.

Roxy, M. K., K. Ritika, P. Terray, R. Murtugudde, K. Ashok, and B. Goswami, 2015: Drying of Indian subcontinent by rapid Indian Ocean warming and a weakening land-sea thermal gradient. Nat. Commun., 6, 7423, https://doi.org/10.1038/ncomms8423.

Saha, K., and S. Bavadekar, 1973: Water vapour budget and precipitation over the Arabian Sea during the northern summer. Quart. J. Roy. Meteor. Soc., 99, 273-278, https://doi.org/ 10.1002/qj.49709942006.

Sikka, D., and S. Gadgil, 1980: On the maximum cloud zone and the ITCZ over Indian, longitudes during the southwest monsoon. Mon. Wea. Rev., 108, 1840-1853, https://doi.org/10.1175/15200493(1980)108<1840:OTMCZA > 2.0.CO;2.

Stohl, A., and P. James, 2004: A Lagrangian analysis of the atmospheric branch of the global water cycle. Part I: Method description, validation, and demonstration for the August 2002 flooding in central Europe. J. Hydrometeor., 5, 656-678, https:// doi.org/10.1175/1525-7541(2004)005<0656:ALAOTA > 2.0.CO;2.

Tuinenburg, O., and J. de Vries, 2017: Irrigation patterns resemble ERA-Interim reanalysis soil moisture additions.
Geophys. Res. Lett., 44, 10341-10348, https://doi.org/10.1002/ 2017 GL074884.

Van der Ent, R., O. Tuinenburg, H.-R. Knoche, H. Kunstmann, and H. Savenije, 2013: Should we use a simple or complex model for moisture recycling and atmospheric moisture tracking? Hydrol. Earth Syst. Sci., 17, 4869-4884, https:// doi.org/10.5194/hess-17-4869-2013.

Vries, P., and K. Döös, 2001: Calculating Lagrangian trajectories using time-dependent velocity fields. J. Atmos. Oceanic Technol., 18, 1092-1101, https://doi.org/10.1175/1520-0426(2001)018<1092: CLTUTD $>2.0 . \mathrm{CO} ; 2$.

Walker, J. M., S. Bordoni, and T. Schneider, 2015: Interannual variability in the large-scale dynamics of the South Asian summer monsoon. J. Climate, 28, 3731-3750, https://doi.org/ 10.1175/JCLI-D-14-00612.1.

Webster, P. J., V. O. Magana, T. Palmer, J. Shukla, R. Tomas, M. Yanai, and T. Yasunari, 1998: Monsoons: Processes, predictability, and the prospects for prediction. J. Geophys. Res. Oceans, 103, 14 451-14 510, https://doi.org/10.1029/97JC02719.

Yoon, J.-H., and T.-C. Chen, 2005: Water vapor budget of the Indian monsoon depression. Tellus, 57A, 770-782, https:// doi.org/10.3402/tellusa.v57i5.14737. 